\title{
Integration strategy for the development of tax mechanisms in the process of state regulation of agriculture
}

\author{
Tatyana Vladimirovna Zyryanova ${ }^{1}$, Olga Alexandrovna Rushickaya ${ }^{2}$, Ekaterina Mihailovna \\ $\mathrm{Kot}^{1}$, and Alexandr Olegovich Zagurskiy ${ }^{1}$ \\ ${ }^{1}$ Ural State Agrarian University, Institute of Economics Finance and management, Department of \\ accounting and audit, 620075, Karl Liebknecht street 42, Yekaterinburg, Russia \\ ${ }^{2}$ Ural State Agrarian University, Institute of Economics Finance and management, Department of \\ management and economic theory, 620075, Karl Liebknecht street 42, Yekaterinburg, Russia
}

\begin{abstract}
This article presents the author's view on the integration strategy for the development of tax mechanisms in agriculture. The importance and necessity of developing such a tax mechanism are updated, and arguments in favor of such a development strategy are presented. The authors proposed a new scientific term that characterizes the process of harmonization of tax regulation mechanisms in related sectors of the economy. The ways and directions of such harmonization within the agricultural and agro-industrial sector of the Russian economy as a whole are proposed. The analysis of the current state of the tax environment for Russian agricultural producers has been carried out, and the main factors for strengthening and reducing the growth rate of the agricultural sector have been identified. Based on the results of the study, the author gives an opinion on the current state of the tax environment in relation to agriculture.
\end{abstract}

\section{Introduction}

In the complex of state measures aimed at maintaining the sustainable development of the agricultural sector, the leading place is given to improving the tax system. The modern tax policy of Russia does not place the agricultural sector on a par with other types of economic activity. Therefore, the agricultural producer in relation to the state is in a preferential position, which is manifested in the fact that the producer has the right to apply a special tax regime. Regulation of agriculture within the framework of General tax legislation is not possible, which is primarily due to the fact that farms do not have a sufficient level of profitability to pay a significant number of taxes. Thus, the need to use a special regime in the agricultural taxation system is caused by objective reasons.

The need to reform the system of state tax regulation of agriculture indicates the need for a qualitative review of the role of tax instruments in the process of stimulating the development of the agricultural industry and eliminating the barriers that arise in the process of its intersectoral integration. When conducting tax policy aimed at cross-sectoral integration in the agricultural sector of the economy, the close relationship between the types of economic

\footnotetext{
${ }^{1}$ Corresponding author: zagurskiy-ao@yandex.ru
} 
activities, as well as related industries of the processing and service sectors of the economy should be taken into account. The integration process as a form of business Association of a number of agricultural enterprises within the horizontal and vertical relationship in financial and economic relations is one of the strategic goals in the development of tax regulation mechanisms. No doubt that tax mechanisms should be oriented towards promoting integration processes in agriculture and agriculture.

The creation of an integration strategy for the development of the system and mechanisms of tax regulation should be accompanied by studies of existing integration entities, assessment and study of their institutional environment, an important element of which is the current tax system.

As part of the reform of the system of tax regulation of the agricultural industry, aimed at the development of integration processes, we suggest using the term "intra-industry fiscal integration".

Intra-industry fiscal integration is a process of harmonization of taxation mechanisms in individual and related sectors of the national economy to prevent the emergence of any financial and administrative barriers in the process of their interaction.

The importance of intra-industry fiscal integration lies in the fact that most of the GDP created by the industry is redistributed through the tax system, and the success of the tax regulation process itself will depend on how effectively this process is established[1].

\section{Materials and methods}

The effect of intraindustrial fiscal integration on agriculture and the agricultural sector as a whole should be expressed:

1. in reducing prices for products produced by the national producer by optimizing the processes of tax interaction between economic entities;

2. in strengthening intra-industry competition by equalizing tax conditions between all subjects of the national economy[2];

3 . in the growth of production volumes and increasing demand for agricultural products produced by the national producer due to the reduction of tax barriers between economic entities[3];

4. in increasing the contribution of the agricultural sector to GRP and GDP by increasing production volumes at the optimal level of tax restrictions.

The key place in this form of integration is given to the harmonization of relations on the issue of indirect taxation, and in the case of Russia, relations on the calculation and payment of value added tax (hereinafter-VAT).

VAT, as a universal form of turnover tax, is a multi-level tax that taxes all stages of product movement, levied at all stages of its use and sale, and, as a result, evenly distributes the tax burden among all economic entities[4].

An important requirement for the formation of a tax system for strategically important sectors of the economy is the neutrality of taxation. Thus, according to I. O. Lunina, consumption taxes are more neutral than income taxes[5].

Some authors even point out that VAT should not be included in the calculation of the tax burden of producers, referring to the fact that the real VAT payers are final consumers[6].

We believe that this statement is true, but only if the VAT included in the product price does not lead to a loss of competitiveness and does not affect the level of final consumption, which is not possible[7].

We have a different opinion about the impact of indirect taxation on the economy of production sectors. The level of indirect tax burden has a direct impact on the purchasing power of the final consumer, who is the final link in the process of functioning of the economy. For example, the presence of VAT in the cost of products produced by the VAT payer, in 
competition with organizations that do not pay VAT, forces the former to adjust prices downward to the level of competitive, which accordingly creates the appearance of falling revenues[8].

The integration of the agricultural sector should take a priority place in the regional and national economy. In this regard, it is necessary to provide special mechanisms for fiscal integration of agricultural entities[9].

In the field of agriculture, the most prominent feature of VAT should be to ensure and maintain and protect the industry in the process of its fiscal integration, as well as focus on simplifying the tax process.

In our opinion, the fiscal integration of the agricultural sector in Russia should take place through the use of institutions of special tax regimes, namely the UACT. The importance of this tax regime for the industry is to ensure uniform tax conditions for the functioning of the agricultural industry.

We proposed to generate from UAT main tool of fiscal integration of the agricultural sector, by ensuring such conditions of its application, to attract the vast majority of agricultural producers to its use, thus forming UAT center industry fiscal integration of the agricultural sector.

In addition, tax policies to maintain the sustainable development of all intersectoral agroindustrial complex, in determining the regulating mechanisms of the agricultural sector, should take into account internal, cross-sectoral links with "related" industries as the manufacture of mineral resources, processing of agricultural raw materials and infrastructure unit agroindustrial complex.

The effectiveness of tax policy in agribusiness should be evaluated by its impact on the formation of the cost structure in the model of inter-industry balance of agribusiness, the principles of construction of which in the formation of tax policy in relation to agribusiness are presented in figure 1.

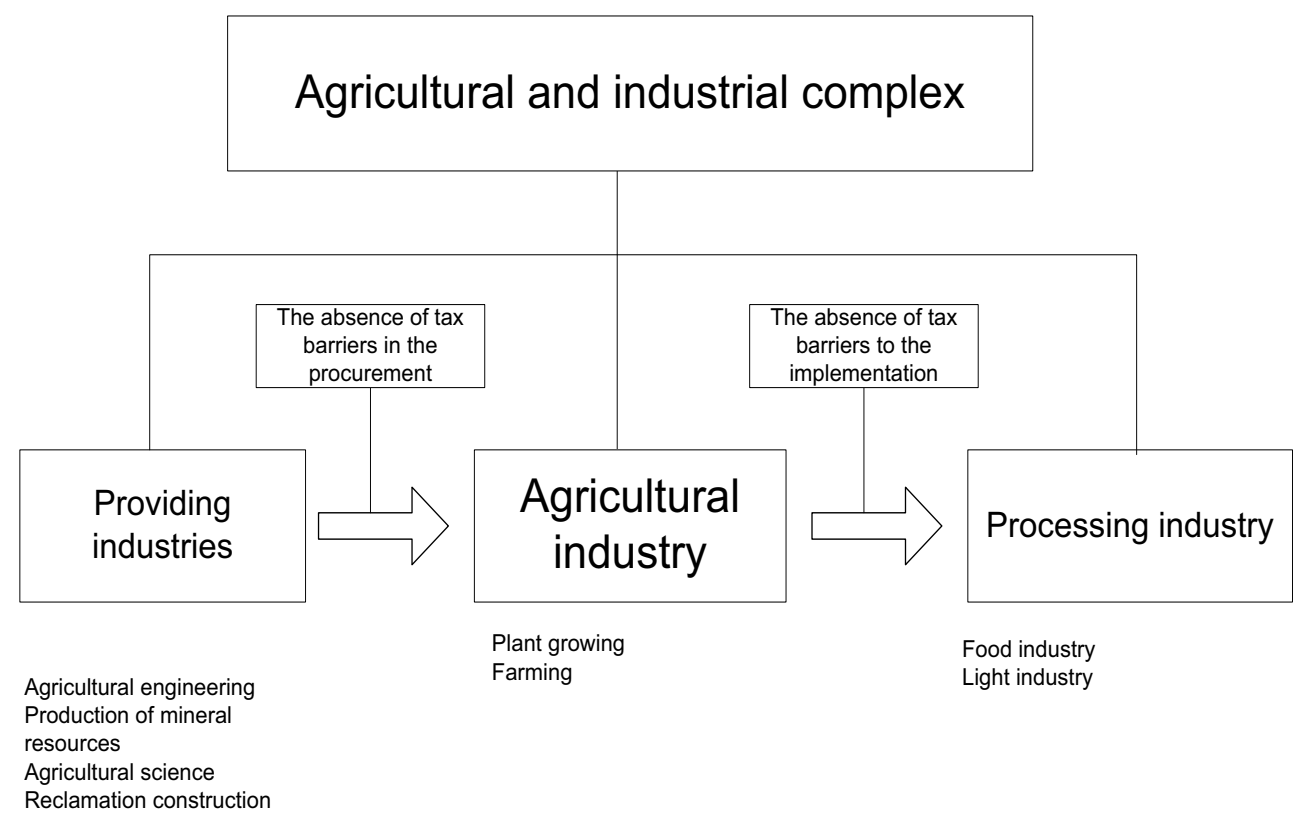

Fig. 1. the Principle of building intersectoral links in the formation of tax policy in the agricultural sector 
Studying the impact of taxes on the structure of the inter-industry balance, V. V. Leontiev identified taxes as the main component of the market price, which forms the added value paid by the buyer of the product and has its own valuation[10].

At the same time, the scientist assigned a special role to VAT, highlighting it as a separate component that forms the relationship between the buyer's price, the seller's price and the basic price of the product, which is manifested in the relationship of calculating and paying indirect taxes.

An inefficient tax system is characterized, among other things, by a high impact on the structure of the inter-industry balance sheet, estimated using the "cost-output" model, which, in the end, is reflected in the cost of the final industry products.

Depending on the proportion in which value added is distributed between the state and producers, the role of the tax mechanism in pricing changes [11].

Highlighting factors such as the size and structure of production, as well as the elasticity of demand, the impact of taxation on the pricing process may increase or decrease depending on the influence of each factor[12].

Final industry products in agriculture can be described as a measure of participation of a certain industry in the process of agricultural production, as certified products of this link. To take into account the role of taxes in the formation of the value of agricultural products, their form of reflection in the newly created value link must be taken into account.

Until recently, the Russian form of cross-industry balance of agriculture was characterized by a high share in the cost of production of components not related to agriculture. According to some scientists, this percentage exceeded $60 \%[13]$. There is no doubt that taxes have a significant impact on the formation of the non-agricultural share when implementing interindustry interaction procedures.

The level of the tax component in cross-industry turnover, especially for indirect taxes, largely determines the level of price for the final consumer. The amount of taxes in intraindustry turnover can be reflected by the following formula:

$$
\mathrm{Peu}=\mathrm{Ciit}+\mathrm{Tcp}+\mathrm{TM}+\mathrm{ET}+\mathrm{ETic}
$$

where:

Peu - product price for the end user;

Ciit - costs in intra-industry turnover;

Tcp - taxes included in the cost of production in the process of intra-industry turnover;

$\mathrm{TM}$ - trade margin at the stages of intra-industry turnover;

ET - the amount of indirect taxes included in the cost of products (VAT, excise taxes);

ETic - indirect taxes recorded as expenses in the process of intra-industry turnover (VAT, excise taxes).

The task of the optimally constructed mechanism of tax regulation of agriculture and agriculture is to minimize the impact of the ETic indicator on the formation of the cost of the final product.

The value of the ETic indicator in the process of intra-industry turnover arises in the process of contradictions in the interaction of two different tax regimes, in terms of indirect taxes taken into account in the cost of purchased products. A similar phenomenon may occur when an organization that is a VAT defaulter purchases products from a VAT-paying organization. In such a scenario, input VAT, which the buyer organization cannot accept for deduction, reflects it in the cost price, i.e. it includes it in the price of the product, thus unnecessarily increasing the scale of intra-industry turnover.

The appearance of this phenomenon in the process of inter-industry interaction has a negative impact on the cost structure of the inter-industry balance, the cost of the industry's final products and the price for the final consumer. 
The formation of a single, unified tax mechanism for the agricultural sector that can optimize the process of forming an inter-industry balance, which is a strategically important task in the development of the national agricultural and agro-industrial sector of the economy. In our opinion, at the moment, only the ECN is able to become such a mechanism.

The tax policy in relation to agriculture and agriculture should be able to stop all the negative aspects associated with the interaction of agriculture with other branches of agriculture, which, in the end, may have negative tax consequences for all areas of agriculture.

As we believe, at the present stage of development of the agricultural economy, the UACT has already taken place as a single industry tax regime, which is aimed at favoring the development of the agricultural sector. However, we note that there are still some contradictions in the functioning of the UACT in the tax field of Russia. To date, such contradictions are gradually being eliminated, increasingly integrating a significant number of agricultural producers around the UACT.

The UACT regime is a universal tool for tax regulation of the agricultural economy by the authorities. With its application, it became possible to implement fiscal integration both in terms of direct taxation (tax on income reduced by expenses, tax on property of organizations) and in terms of indirect taxation (VAT).

The UACT should be considered not just as a kind of special tax regime, but as a separate branch tax system, the reform process of which should be aimed at further fiscal integration of the agricultural sector.

We attach particular importance to ensuring consistency in the implementation of the policy of fiscal integration of the agricultural sector of the economy. The unsystematic functioning of tax mechanisms is a key problem in the development of the agricultural sector [14].

In this regard, we identify four areas in which the fiscal integration of the agricultural sector around the ESCs should take place (see figure 2).

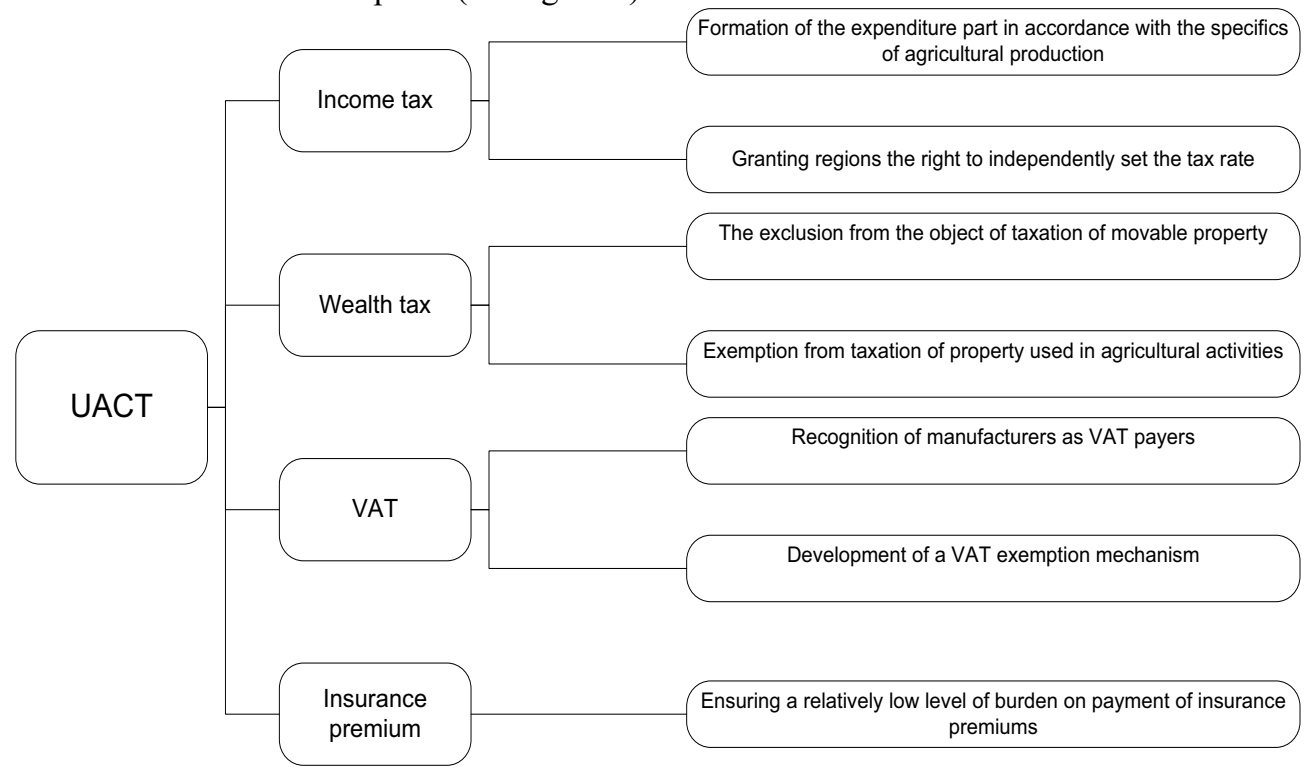

Fig. 2. Directions of fiscal integration

In the direction of" income tax", it is necessary to continue structuring the closed list of expenses involved in the formation of the tax base for agricultural producers. It is necessary to adapt this list as much as possible and bring it closer to the actual conditions of agricultural activity in modern Russian conditions. 
In addition to improving the formation of the expenditure part, this direction involves expanding the possibilities of tax regulation and changing the regulator, namely, granting the right to regional authorities to independently set the size of the tax rate.

The "property tax" direction assumes a reduction in the fiscal burden on the main production assets of agricultural producers, namely, the recognition of agricultural objects as privileged, as well as the exclusion of movable property from the taxation objects. The result of this direction should be an increase in investment activity in fixed assets by reducing the cost of paying property tax.

One of the most important areas is the inclusion of producers in the system of relations for calculating and paying VAT in order to prevent their abuse and unhindered integration into economic relations with VAT payers. For this purpose, it is important to recognize manufacturers that use the UACT as VAT payers. But in addition, it is necessary to ensure that a number of manufacturers retain their right to exemption from VAT, and for these purposes, to improve and adapt the mechanism of such exemption to modern conditions.

To date, the above-mentioned directions have already been implemented or are at the initial stage. However, we have not found any steps towards the implementation of the "insurance premiums" direction, namely, ensuring a relatively low level of burden on the payment of insurance premiums. It is necessary to note the importance of creating a special mechanism for collecting insurance premiums from agricultural producers that do not allow excessive load on the wage Fund.

An additional benefit from the implementation of intra-industry integration around the UACT will be an increase in the level of economic health of the regions. The leaders in terms of economic health are regions with fairly high revenues from taxes on total income, which include the UACT. Despite the fact that tax policy in respect of agriculture should be stimulatory for some agricultural regions of Russia, fiscal integration around UAT will be the basis of improvement in economic efficiency that is highly relevant in the high degree of differentiation of regions in terms of economic development. Thus, according to a study by the expert rating Agency, traditionally agricultural regions such as the Kurgan region, Stavropol territory, Saratov region, the Republic of Kalmykia and a number of other regions are characterized by a fairly low level of development[15]. This phenomenon is characterized by a fairly low level of tax revenues from small and medium-sized businesses, which demonstrates the weak development of entrepreneurial initiative and business activity in these regions, especially in agriculture[16].

While investigating the current problems of applying tax regulation mechanisms within the framework of state influence, we have identified the main modern tax factors that have both a positive and negative impact on economic growth and business activity of the agricultural industry and the agri-food sector, or how we have defined them as factors for increasing growth rates and factors for reducing growth rates (see figure 3 ).

We present these factors as a model of a mutually compensating nature, in which the identified tax factors of a decrease in growth rates are compensated by factors of an increase in growth rates. And as can be seen from the presented figure, both quantitatively and qualitatively, the factors of increasing growth rates exceed the factors of decreasing growth rates, which allows us to assess the current direction of improving the tax regulation system and, accordingly, the state policy of tax regulation, as aimed at achieving high growth rates and achieving high results in the agriculture and agri-food sector among the branches of the national economy of Russia. 


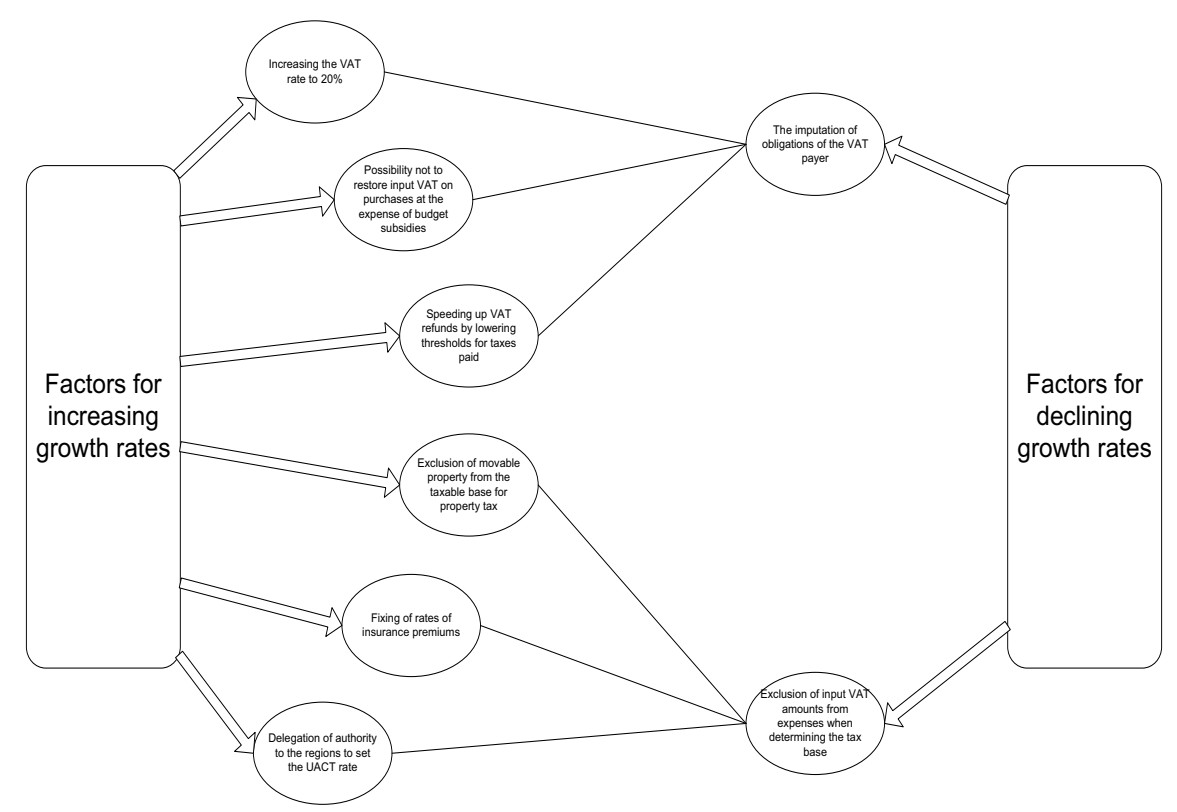

Fig. 3. Model of mutually compensating interaction of factors of growth rates of agriculture and agri-food sector

\section{Results and discussion}

In modern Russian conditions, the tax system for agriculture in the agricultural sector of the economy should be aimed primarily at stimulating the expansion of production activities, investment in fixed assets, stimulating demand for agricultural products, developing competition, etc.at the same time, providing favorable tax conditions for some subjects should not be accompanied by infringement of the interests of others. It is advisable to conduct separate activities in the field of taxation for subjects of different levels. The state should aim at providing optimal tax conditions for micro, small, medium and large businesses, since each of the levels is important for the socio-economic and political development of a particular region and the state as a whole.

\section{References}

1. M. Richard, Tax Coordination in the European Community, 227-251 (1987)

2. Scott Greenberg, Corporate Tax foundation fiscal fact (2016)

3. Sustainable Food and Agriculture 1st Edition, (Academic Press, 2018)

4. E. T. Prokopchuk, Prospects of Science and Education, 1, 278-283 (2014)

5. I. O. Lunina, Finance of Ukraine, 1, 17-27 (2009)

6. T. G. Davletshin, International accounting, 17, 991 - 1003 (2017)

7. T. V. Zyryanova, O. A. Zagurskiy, Finance, 7, 33 - 37 (2018)

8. T. V. Zyryanova, A. O. Zagurskiy, Wschodnioeuropejskie Czasopismo Naukowe (East European Scientific Journal), 12(40), 38-41 (2018)

9. Y. G. Tyurina, M. A. Troyanskaya, Economics: yesterday, today, tomorrow, 3, 251-259 (2016)

10. V. Leontiev, Research theories, facts, and politics, 415 (Politizdat,1990) 
11. The World Bank Economic Review, 3, 493-511 (1991)

12. Bulletin of the Tomsk state University, 318, 176-178 (2009)

13. E. A. Zakharova, Nikonovsky readings, 14, 61-64 (2009)

14. L. D. Tulush, Nikonovsky readings, 18, 414-416 (2013)

15. Economic health of Russian regions. The current level and dynamics of changes in the Research of the rating Agency Expert.

16. Rating of the effectiveness of regional tax policy at the end of 2018 PricewaterhouseCoopers (2019) 